\title{
Automatic Irrigation System using GPRS Module
}

\author{
Pankaj Desai ${ }^{1}$, Prof. Yadav P. D ${ }^{2}$ \\ Student -Bachelor of Engineering, Electronics \& Telecommunication Engineering Department, Dr. Daulatrao Aher \\ College of Engineering, Karad, Maharashtra, India ${ }^{1}$ \\ Assistant Professor, Electronics \& Telecommunication Engineering Department, Dr. Daulatrao Aher College of \\ Engineering, Karad, Maharashtra, India ${ }^{2}$
}

\begin{abstract}
Agriculture is source of livelihood of majority Indians and it also has great impact on economy of the country. In dry areas where there is inadequate rainfall or when a farmer is not aware how use water when there is water storage or when there is no water storage irrigation become studious. Wireless sensors networks is an automated irrigation system used to enhance the use of water for agricultural crops. System consists of a wireless network that is the soil moisture sensor placed under the soil where plants roots are reached which is distributed network. The system has water level sensor which will indicate the presence of water level in tank. Gateway unit manages information related to the sensors triggers actuators and data transmitted using GPRS module. A software application was developed by predetermining the threshold values of soil miniature and water level that was programmed into an arm controller. The data from GSM module is transmitted or received from or to mobile using software application or normal texting mode which optimizes the use of water quantity. Control voltage fluctuation to get system work properly.
\end{abstract}

Keywords: GSM system, water level sensor, soil moisture sensor.

\section{INTRODUCTION}

Continuous increasing food demand requires the huge improvement in food production technology. In a country like India, where the economy is mainly based on agriculture and the weather circumstance are isotropic, still we are unable to make full use of agricultural resources. The main reason is the insufficiency of rains \& scarcity of land reservoir water. Continuous water extraction from earth is decreasing the water level due to which lot of land is coming slowly in the zones of unirrigated land. In modern drip irrigation systems, the most significant advantage is that water is supplied to root zone of plants drip irrigation due to which a large quantity of water is saved. At the current era, the farmers have been using irrigation techniques in our country through manual control in which farmers irrigate the land at the regular intervals. This process system sometimes consumes large amount water or sometimes the water reaches late because of this crop get dried. Lack of water can be detrimental to plants before visible wilting take place. Slower growth rate, lighter weight fruit because slight water deficiency. This problem can be perfectly rectified if we use automatic microcontroller based drip irrigation system in which the irrigation will occurs only when there will be intense requirement of water.

\section{SYSTEM DISCREPTION}

\section{WATER LEVEL SENSOR:}

Water level sensors (also known as transceivers when they both send and receive) work on a principle similar to radar which evaluate attributes of a target by interpreting the echoes from radio or sound waves respectively. Ultrasonic sensors produced high frequency sound waves and evaluate the echo which is received back by the sensor. Sensors calculate time interval between sending the signal and receiving echo to determine the distance to an object. This technology can be used for measuring: direction and wind speed, tank or channel level, and speed through air or water. In this case to measure water level ultrasonic sensors are used.

\section{RELAY:}

Relay is an electrically operated switch. The relay is used here to switch the motor to ON /OFF position according to the water requirements. Current flowing through the coil of relay creates magnetic field which attracts a lever and changes the switch contacts. The coil current can be on/off so relays have two switch positions and they are double throw switches.

\section{LCD Display:}

The LCD Display is used to provide the user with digital values converted by the PIC microcontroller. LCD driver is a link between microcontroller and LCD. It is important to interface the LCD according to the driver specification. To understand the algorithm of LCD interfacing user requires datasheet of both LCD and LCD driver. In LCD initialization you have to send command bytes to LCD.

\section{GPRS:}

GPRS stands for General Packet Radio Service. GPRS is technologies to improve $2 \mathrm{G}$ phones to enable them for 
transferring data at higher speed. GPRS allows mobile when soil is dry then motor is on water supply to crops. As phones to remain connected to network and transfer we operate the system manually as by using mobile phone requested data, e.g. when you receive MMS from other as we require. We operate system by making a call by mobile phone, you do not need to press a button to check simply pressing the 1 button and off. When motor is on we if you have any new MMS. GPRS technology can supply get the sms. Soil moisture content has been detected using up to $32 \mathrm{kbps}$ to $48 \mathrm{kbps}$. One of the features of GPRS acoustic based technique was developed. The main motive technology which makes it even more useful and practical of this technique is improvement for measure soil moisture is that data can transfer during call and there is no in real time method. This technique based on relationship requirement of disconnecting call to receiving incoming or between two quantities i.e. velocity of sound and the outgoing data.

\section{MICROCONTROLLER:}

The arm7 processor describes a family of RISC architecture. RM processors need significantly fewer transistors than processors that would typically be establish in a traditional computer. The benefits of this approach are lower costs, less heat, and less power usage, traits that are desirable for use in light, battery-powered devices and tablet computers. PIC is a family of modified Harvard architecture microcontrollers developed by Microchip Technology, derived from the PIC1650 originally developed by General Instrument's Microelectronics Division. The name PIC referred to "Peripheral Interface Controller" Peripheral interface controller is the most powerful microcontroller which is a 40pin device which is used as RISC architecture. One advantage of reduced instruction set computers is that they can execute their instructions very fast because the instructions are so simple. Another, likely more important advantage, is that RISC chips need fewer transistors, which makes them cheaper to design and produce.

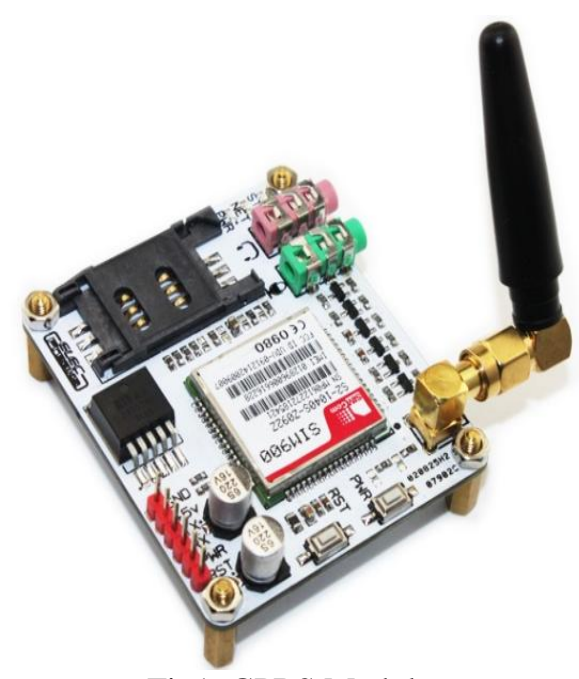

Fig1. GPRS Module.

\section{III.WORKING PRINCIPLE}

This system can operate manually as well as automatically. In this system we use two sensors one is water level sensor and another is soil moisture sensor. These two sensors are highly sensitive. In this system soil moisture sensor is put in soil for detecting the soil is dry or wet. When soil is wet then all motors are off condition and degree of saturation with water in soils. This experiment establishes that the speed of sound decreases with the moisture content following, depending on the kind of soil.

\section{BLOCK DIAGRAM}

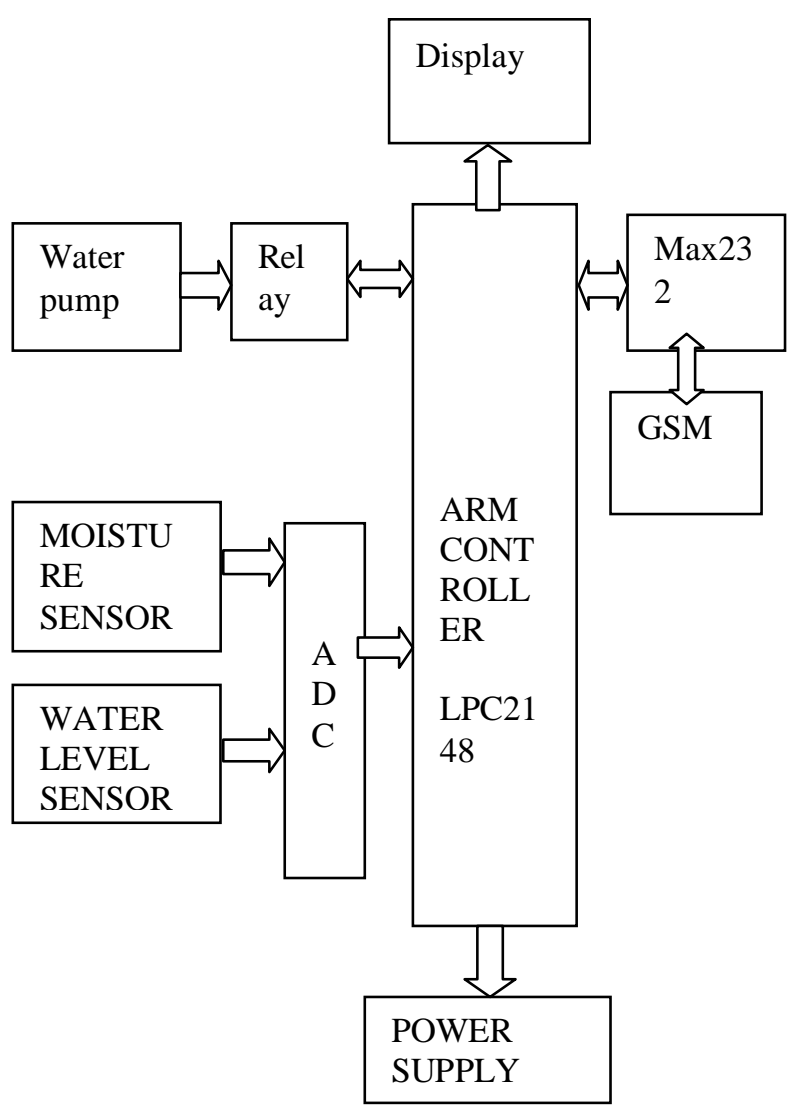

In this paper, soil moisture content has been detected using auditory based technique was developed. The main propose of this technique is development for measure soil moisture in real time method. This experiment found that the speed of sound decreases with the moisture content following, depending on the kind of soil. In this paper design model of automatic irrigation system which is based on microcontroller and source of power supply. Various sensors are placed in paddy zone. Water level sensors sense water level continuously and send the information to farmer through cellular phone. Without going in paddy field Farmer controls the motor using cellular phone. If the water level reaches at danger level, automatically motor will be off without conformation of farmer. Automatic system based on ARM and GPRS 
technology was used for communication. Irrigation system provides foe adequate irrigation in particular area which is real time. Soil moisture sensor placed in root zone in paddy field and sense water level. The system was set up using ARM7TDMI core and GPRS. GPRS is an important parts of these this system. System communicates using GPRS. GPRS operate through SMS and is a link between ARM processor and centralized unit. This system detects climate condition and field condition in real time. This information send to user in the form of SMS and GSM modem is controlled with the help of standard set of AT (Attention) commands. These commands are used to control majority of the functions of GPRS model. In the paper, automatic irrigation technique irrigated using wireless sensor network. Sensors are placed in farm and sense continuously and collect he information. This information stored at center monitor and also passes to data collection interface and then transmits to the wireless sensor node.

\section{IV.RESULT}

This project is operates as manually as well as 6 . automatically. In manual operation we turn on water pump as we required and in another mode water pump will on depends on conditions in manual mode we turn on water pump by mobile calling, we simple make a call to no. which is placed in gps model and press some button, also we off water pump by making a call. In automatic mode water pump is turn on water pump depends on condition, those conditions are soil is dry or wet. When soil is dry water pump is on and when soil is wet then water pump is off.

\section{CONCLUSION}

The primary applications for this project are for gardeners and farmers who do not have enough time to water their crops/plants. It also covers those farmers who are wasteful of water during irrigation. The project can be extended to greenhouses where manual supervision is few and far in between. The principle can be extended to create fully automated farmlands and gardeners. Combined with the principle of rain water harvesting, if it is applied in right mannerist could lead to huge water savings. In agricultural lands with severe shortage of rainfall, this model can be successfully applied to achieve great results with most types of soil.

\section{VI.LIMITATION AND FUTURE SCOPE}

We cannot use this for three phase power supply because of fluctuation in our supply and because of this fluctuation motor will damage. We also implement this system for three phases by hard working on system calculation and by minimizing fluctuation of supply. This project is very useful for farmers and very useful for preventing water wastage.

\section{ACKNOWLEDGMENT}

Irrigation becomes easy, accurate and practical with the idea above shared and can be implemented in agricultural fields in future to promote agriculture to next level. The output from moisture sensor and level system plays important role in producing the output.

\section{REFERENCES}

1. Quan Minh Vu, "Automated Wireless Greenhouse Management System", Master of Engineering in Electronics and Computer Systems, Massy University, Palmerston North, New Zealand, June 2011

2. Jose Luis Guzman, "Simulation of Greenhouse Climate Monitoring and Control with Wireless Sensor Network and Event-based Control", Department of Computer Science and Automatic Control, UNED C/. Juan Del Rosal, Madrid, Spain

3. Masayu Binti Hussein, "Automatic Greenhouse Watering System Using Microcontroller" University Malaysia Pahang

4. David Whiting (CSU Extension, retired) with Michael Roll and Larry Vickerman (former CSU Extension employees). Artwork by Scott Johnson and David Whiting

5. Md. Anisul Hoque, "Greenhouse Effect", Leominster Road, London, UK, The Daily Star

http://www.gpnmag.com/greenhouse-light

http://www.ag.auburn.edu/hort/landscape/lightintensityquality.html http://www.electronics-tutorials.ws/io/io_4.html

9. By Anthony J. De Blasi "Greenhouse Growing: Tips for Basic Greenhouse Cultivation" Mother Earth News

10. "Light and Lighting Control in Greenhouse", Argus Control System Limited, White Rock, Canada

11. http://www.robotshop.com/media/files/pdf/grove-moisture-sensorsen92355p.pdf 